\title{
Historic Scientific Instruments in the Old Ashmolean Museum, Oxford.
}

$\mathrm{O}^{\mathrm{N}}$ Tuesday, May 5, the Old Ashmolean Museum at Oxford was reopened as a home for old scientific instruments, especially the magnificent collection presented to the University by Mr. Lewis Evans, on whom the honorary degree of D.Litt. was first fittingly conferred. After this, a large and brilliant gathering assembled in the Divinity School under the chairmanship of the Vice-Chancellor to hear an account of the collection from Mr. R. W. T. Gunther, fellow of Magdalen, who has been appointed curator; and an address from the Earl of Cravford and Balcarres, president of the Society of Antiquaries, who performed the opening ceremony.

The Old Ashmolean Building, which embodies many of the features of Wren's design for a College of Science, was originally opened on May 21, I683, by the Duke of York, afterwards James II. ; and it was pleasant to have at this second opening, nearly $25^{\circ}$ years later, a cordial message from the present Duke of York, transmitted through a specially appointed representative, the president of Magdalen. Lord Crawford, in some inspiring words, welcomed the dispelling of the mischievous fallacy that there is a necessary antagonism between science and art; for in the present exhibition the two are practically combined. Instruments that have become scientifically obsolete survive as beautiful works of art.

The company had ample opportunity to verify this statement; for many of the exhibits have indeed great beauty of workmanship. A little crucifix, the arms and sides of which constitute a vertical sundial, while the interior is filled with drawing instruments, came in for special admiration. Its instruments were spread out beside it, and their number almost suggested that it might be difficult to get back the "genie into the bottle." Dr. Evans has told us that his collection began (when he was only eleven !) with sundials; and though it expanded later to include astrolabes and other instruments of precision, it took him twenty years to find his first astrolabe. He was really trying all that time to get one, and prepared to spend money on it, but there were none to be had. In view of the number he has now accumulated, this is very surprising. An interesting development of his collecting tastes is represented by a very fine set of gunnery levels, specially admired by another collector of these treasures.

Besides the Lewis Evans collection itself, there are many other loans and gifts, attracted partly by the new and splendid opportunities for presentation, and partly no doubt by Mr. Gunther's persuasiveness. Miss Willmott has lent a remarkable astronomical clock, with an astrolabe as dial, two hands to show the positions of the sun and moon, and a mean time clock at the back-all beautifully ornamented. Christ Church and Oriel have both lent important collections - the former a collection of orreries. Doubtless other gifts and loans will come. Mr. Gunther was specially gratified to receive a note from Mr. E. B. Knobel after his visit: "I see from your catalogue you want a Davis's Backstaff: I'll send you one." There are copies of two Galilean telescopes and a Hooke microscope which come from special funds. Perhaps the best example of the advantages brought by the new opportunities is the conjunction of (a) the first circular slide rule ( 1632 ), invented by Oughtred, (b) portraits of Oughtred and of Elias Allen, the maker, (c) two books on the subject by Oughtred and Allen. Now $(a)$ is a loan from St. John's College, (b) from the Hope collection of portraits in Oxford, while $(c)$ are from the Evans collection. Thus we see the value of Oxford as a collecting and combining medium; but again, we must not undervalue the knowledge which Mr. Gunther had gradually acquired of the (formerly) hidden resources of Oxford.

We may regard Tuesday's ceremony as the very satisfactory ending of a period of doubt and difficulty with regard to the Lewis Evans collection. The joys of collecting are great; but there comes a time when some anxiety as to the ultimate fate of the collection must temper those joys. Such anxieties must now have been dissipated; and for this happy result we have in great measure to thank the ViceChancellor, without whose sympathy and liberal views of the functions of a University even Mr. Gunther's energy might have failed to clear the path from difficulties.

Two points of detail may be mentioned. The little catalogue of the instruments is on sale in the old Ashmolean Building, not in the Ashmolean Museum as (erroneously) printed on the cover. The danger of this confusion is well-nigh unavoidable. Secondly, those interested will find some really excellent pictures of building and exhibits in Country Life for May 9.
H. H. T

\section{Growth Stages of a Crustacean.}

FVERY student of zoology has some acquaintance C with the larval stages of those Crustacea that undergo metamorphosis, but there has hitherto been no detailed account of the changes during growth in any of the species in which development is direct. In the course of researches on the genetics of Gammarus chevreuxi carried out at Plymouth, Mrs. E. W. Sexton found it necessary to have fuller information as to the characters of the successive stages from hatching to maturity. She therefore set herself to the laborious task of studying and depicting, with her well-known artistic skill, complete series of the moulted skins of isolated individuals. The results are now recorded in. a paper (Journ. Marine Biol. Ass., vol. I3, No. 2, pp. $340-396,2$ r pls., I924) which is of unusual interest and importance from several points of view.

Apart from certain changes in the proportions of the body, the differences between the various stages are slight and concern mainly the form, number and position of the hairs and spines on the body and limbs. These trivial differences, however, are remarkably

constant, and by means of them the successive stages can be as sharply defined and as surely recognised as can the larval stages of those Crustacea in which the changes of form are more striking. It is especially noteworthy that this constancy is undisturbed even by considerable changes in the environment. Gammarus chevreuxi will live and breed equally well in fresh, brackish or sea-water; it breeds all the year round, and the winter broods take more than twice as long to reach maturity as do those hatched in the summer; yet " the stages of growth were found to be identical, even to the number and position of the hairs." As these statements are based on the study of more than 3000 moults obtained during a period of twelve years, we may confidently take Mrs. Sexton's word for it.

Sexual maturity is reached by both sexes after the seventh moult. The females continue to grow and to moult without further change of form. The males, however, do not attain their definitive characters until the ninth moult. There are, therefore, three 